\title{
Characterization and Modeling of Supercapacitors Used for Hybrid Electric Energy Storage
}

\author{
Mustapha Elyaqouti \\ Laboratory of Materials and Reneweble Energies \\ (LMER), Ibn Zohr University, Agadir, Morocco
}

\author{
Lahoussine Bouhouch \\ Laboratory of Materials and Reneweble Energies \\ (LMER), Ibn Zohr University, Agadir, Morocco
}

\begin{abstract}
The electricity storage is a major issue due to the intermittency of the renewable energy sources. In general, lead-acid batteries are the most common and widely used electrochemical devices for energy storage.In order to extend the lifetime of these batteries, new and complementary materials were invented, such as supercapacitors, which in some cases led to develop new electric energy storage systems.In this paper, we present a study investigates to characterization and modeling the supercapacitors by using two models, RC-constructor model and multibranch model, under Matlab-Simulink environment. This study led us to predict the electrical behavior of the supercapacitors in electricity production facilities based renewable energy.
\end{abstract}

\section{General Terms}

Super capacitors

\section{Keywords}

Electricity Storage; Supercapacitors; RC-constructor model; Multibranch model

\section{INTRODUCTION}

The electric energy storage devices are useful in many applications such as telecommunications, memory backups, electric and hybrid vehicles, and photovoltaic [1]. The main parameters should considered in these devices are; the stored energy that expressed in watt-hour (Wh) [2],[3], the maximal power that measured in Watts (W), the weight, the sizing, the lifetime, and the initial cost.In general, the classifications reported to these devices are delicate and arbitrary. In fact, according to the energy density and the power density, there are the following electrochemical components categories [4]:

the accumulators that characterized by high energy density and low power density;

the classical capacitors possess high power density but lower energy density;

the supercapacitors or electric double-layer capacitors that possess the characteristics of the accumulators and the classical capacitors.

The renewable energy sources, like wind and solar, require large devices to store the energy. Effectively, the batteries and the supercapacitors have been used in complementary manner to solve the problem of the energy storage. Considering the available instantaneous power and the quantity of the stored energy, the combination of these devices increase the electric energy storage systems. The supercapacitors have high instantaneous, respectively, power and energythan batteries and classical capacitors. Their lifetime is about 1 to 20 year that is high compared to the batteries. The electrochemical capacitors have very high power density but very lower specific energy. Generally, the capacitorsare used for time constants less than few hundreds of milliseconds. In contrary, the batteries have very low power density and high specific energy, and may used for longer times that attempt to one minute.

Indeed, the supercapacitors are particularly ideal for a wide range of renewable energies applications and for energy storage with high efficiency and in a short time (about 1 to 10 s).Further, designing these materials taken into account the reliability and maintenance, where they are fundamentally considered as maintenance-free and do not require expensive testing compared to the batteries that, in particular, need a follow-up evaluation of their state of health $(\mathrm{SOH})$ and charge (SOC).For these raisons these materials are useful for installations based renewable energy sources that, in general, installed outback.

To understand the behavior of a battery or a supercapacitor, it is necessary to create models able to predict their function through simulation. In fact, the study of electric storage systems modeling is very complex as confirmed by many researchers [5], [6]. In the literature, several models were developed to modeling batteries [7], [8]. These models are often represented by an equivalent electric circuit that consists of resistance, capacitance and other cells with fixed or varied parameterization such as charge state and temperature. On the other hand, there are several models were used for modeling supercapacitor function such as RC-constructor model and multibranch model with two or more branches.

This paper is organized as follow: after an introduction, we detailed the proposed models of supecapacitors in section 2 . Then, in section 3, we presented and discuss the obtained results of simulation. Eventually, the conclusion is presented at the end of the manuscript.

\section{SUPERCAPACITORS MODELING}

\subsection{Supercapacitors pack sizing}

Supercapacitor pack is defined as a serial and/or parallel combination of the supercapacitors cells, which it is sized according to the required power and timespan allowed to achieve this power [9]. The supercapacitor pack sizing consists of:

Fixing the nominal voltage and current levels;

Determining the used total capacity of the supercapacitors pack;

Determining the number of cells in $\operatorname{series} N_{s}$ andin parallel $N_{p}$

In this study, the supercapacitors pack (SC) equivalent model consists of equivalent capacity in $\operatorname{series} C_{s c}$ with an equivalent 
resistance $R_{s c}$, as shown in figure 1 .

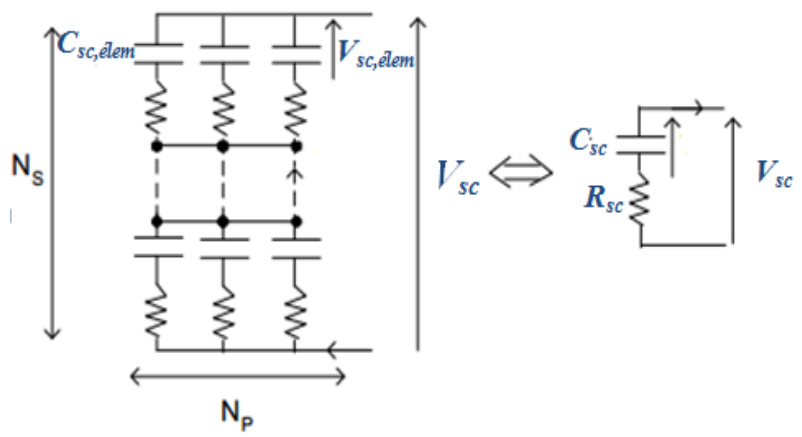

Figure 1:Supercapacitor pack model

The capacity and the global resistance of the supercapacitor pack are evaluated byequations (1) and (2):

$$
\begin{gathered}
C_{s c}=\frac{N_{p}}{N_{s}} C_{s c, e ́ l e m} \\
R_{s c}=\frac{N_{s}}{N_{p}} R_{s c, e ́ l e m}
\end{gathered}
$$

Where $C_{s c, c e l}$ and $R_{s c, c e l}$ are the capacity and the resistance of one supercapacitor cell, respectively.

In addition, the voltage and the current of the SC pack were computed using the equations (3) and (4):

$$
\begin{aligned}
& V_{s c}=N_{s} V_{s c, e ́ l e m} \\
& I_{s c}=N_{p} I_{s c, e ́ l e m}
\end{aligned}
$$

Where $V_{s c}$ et $I_{s c}$ are the supercapacitor pack voltage and current.Respectively, $I_{s c, c e l}$ is the current of one supercapacitor cell, and $V_{s c, c e l} i$ ts voltage.

Further, the stored energy in a supercapacitor was computed using the equation (5):

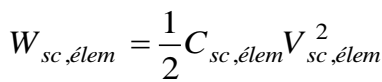

In this study, two constraints were considered [10]:

- The voltage $V_{s c}$ at the supercapacitor terminals should be less than the maximal value $V_{s c, c e l, \max }$ in order to not deteriorate and limit the lifetime of the supercapacitor,

- $\quad$ The all stored energy $W_{s c, c e l}$ is not usable. In fact, if the all energy will used, the voltage at the supercapacitor terminals should be decreased from $V_{s c, \text { cel,max }}$ to $0 \mathrm{~V}$. Consequently, a minimal voltage $V_{s c, c e l, \text { min }}$ should be determined in order to not consume the all stored energy.

Therefore, the usable energy $W_{s c, c e l, u}$ by a supercapacitor is:

$$
W_{s c, \text { élem }}=\frac{1}{2} C_{s c, \text { élem }}\left(V_{s c, \text { élem }, \text { max }}^{2}-V_{s c, \text { élem }, \min }^{2}\right)(6)
$$

So, the available usable energy by a supercapacitor pack that consists of $N$ cells is:

$$
W_{\text {pack }, u}=N W_{S c, \text { élem }}=N_{s} N_{p} W_{s c, \text { élem }, u}
$$

Where, $N_{s}$ and $N_{p}$ are the number of the combined cells in series and parallel, respectively.

The used supercapacitor pack expects to provide the high power demand $P_{\text {charge }}$ during a period of $\Delta t=3 \mathrm{~min}$, thus, inducing a requested power of about $P_{N \text {, charge }}=240 \mathrm{~W}$. Where the extracted energy from the supercapacitor pack is expressed as follow:

$$
P_{N, c h \text { arge }} \Delta t=\eta_{s c} W_{p a c k, u}=\frac{1}{2} \eta_{s c} \frac{N_{p}}{N_{s}} C_{s c, e ́ l e m}\left(V_{s c, \text { max }}^{2}-V_{s c, \text { min }}^{2}\right)
$$

Where, $\eta_{s c}$ is the supercapacitor pack efficiency, which consider the internal losses $\eta_{s c}$ is about 0.9 [11].

The equation (8) allows us to use $75 \%$ of the stored energy in the SC pack if we discharge it from its maximal voltage $V_{s c, \max }$ to half. According to Choi et al [12] the maximal voltage should equal to $80 \%$ of the DC bus voltage. In this study, $V_{b u s}=24 \mathrm{~V}$ which mean $V_{s c, \max }=20 \mathrm{~V}$.

Commonly, the maximal voltage of one supercapacitor cell is $V_{s c, \text { cel,max }}=2.8 \mathrm{~V}$. If we considered $N_{p}=1$, the number of the combined supercapacitor in serie $N_{s}$ is given by the equation in follow:

$$
N_{s}=\frac{V_{s c, \text { max }}}{V_{s c, \text { élem }, \max }}=\frac{20}{2.8}=7.14
$$

If we maximize $N_{s}$ value to $N_{s}=8$, then from equation (8), the capacity of one SC pack cell will be as shown in following equation:

$$
C_{s c, e ́ l e m}=\frac{P_{N, \text { ch } \arg e} \Delta t}{\frac{1}{2} \eta_{s c} \frac{N_{p}}{N_{s}}\left(V_{s c, \text { max }}^{2}-V_{s c, \text { min }}^{2}\right)}=2600 \mathrm{~F}
$$

\subsection{Supercapacitors modeling}

\subsubsection{RC-constructor model}

To modeling the supercapacitors, the constructors use a model of base called "RC-constructor". In this case, each suercapacitor cell consists of a capacitor in $\operatorname{serie} C_{s c, c e l}$ with a resistance $R_{s c, c e l}($ Figure 1)

The RC-constructor model is usuallyused in the context of theenergical systems functional modeling. Also, it is used to establish the technical sheets of the supercapacitors [13],[14].

The resistance $R_{s c, c e l}$ and the capacity $C_{s c, c e l}$ values can be determined through charge/discharge cycles in succession. The figure 2 shows the voltage $V_{s c, c e l}$ curve during one cycle of charge/discharge. 


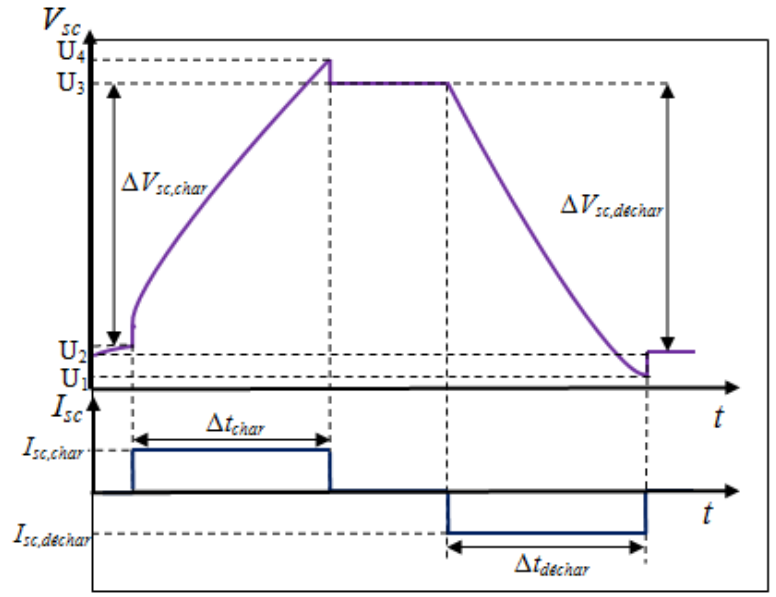

Figure 2 : Evolution of $V_{s c, c e l}$ in funtion of charge/discharge times and method of RC-constructor model parameters determination $\left(\boldsymbol{R}_{s c, c e l}\right.$ et $\left.C_{s c, c e l}\right)$

Indeed, during charge phase, the capacity $C_{s c, c e l, c h a r}$ is given as follow:

$$
C_{s c, e ́ l e m, \text { char }}=I_{s c, \text { char }} \frac{\Delta t_{\text {char }}}{\Delta V_{s c, \text { char }}}
$$

In contrast, during same charge phase, the resistance $R_{s c, c e l, c h a r}$ in serie is determined through the observed voltage drop at time of the current discharge application [15] according to the following equation:

$$
R_{s c, e ́ l e m, c h a r}=\frac{U_{4}-U_{3}}{I_{s c, c h a r}}
$$

Furthermore, during the discharge phase, the capacity $C_{s c, \text { cele,disc }}$ and the resistance $R_{s c, \text { celdisc }}$ of the used model are given as shown in following equations:

$$
\begin{aligned}
& C_{s c \text {,élem, déch }}=I_{s c, \text { déch }} \frac{\Delta t_{\text {déchar }}}{\Delta V_{s c, \text { déchar }}} \\
& R_{s c \text {,élem, déch }}=\frac{U_{2}-U_{1}}{I_{s c, \text { déch }}}
\end{aligned}
$$

In this study, we searching to find the voltage $V_{s c, c e l}$ in function of resistance $R_{s c, c e l}$ and capacity $C_{s c, c e}$ of the RCconstructor model through simulate it in Matlab-Simulink environment (Figure 3).

In fact, we can compute the voltage $V_{s c, c e l}$ by using the equation (15).

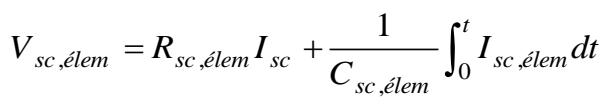

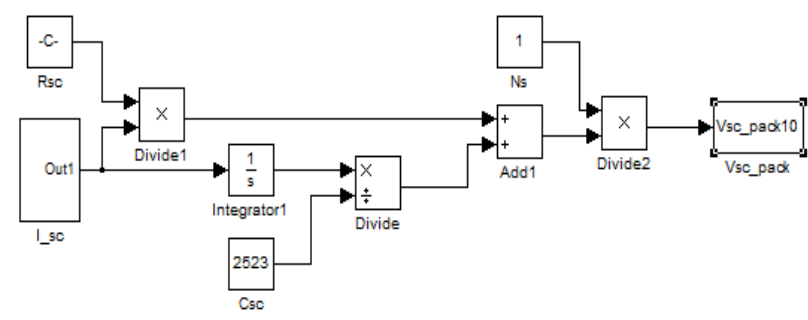

Figure 3: Simplified scheme of the RC-constructor model in Matlab-Simulink

\subsubsection{Multibranchmodel}

\subsubsection{Presentation of the "multibranch" model}

The multibranch model was reported by some authors [16] This model consists of two parts, as presented in figure 4:

- The equivalent nonlinear transmission line at the total resistance $\mathrm{R}_{L T}$ and total capacity $C_{L T}$, describing the electric and energy behavior of the supercapacitor at short times.

- Some RC cells allowing to apprehend the behavior at long times.

To establish the multibranch model in any software's of electric circuit simulation, the transmission line should decomposed into an access resistance $R_{1}$ and a finite number of network of $n$ identic branches $R_{i} C_{i}$, e.g. $R_{i}=R_{L T} / n$ et $C_{i}=C_{L T} / n$, pour $i>1[16]$.

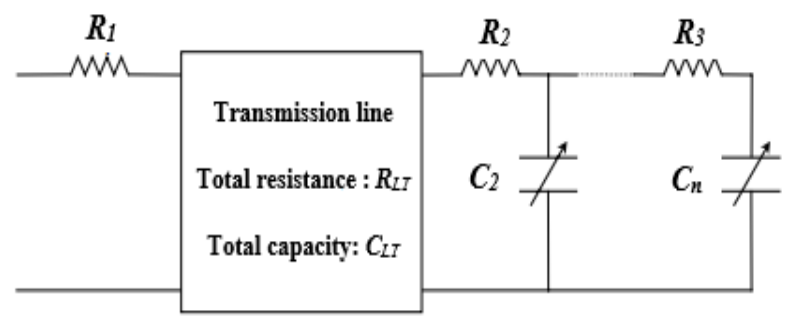

Figure 4:Multibranch behavior model of a supercapacitor

\subsubsection{Parameters model identification}

In following lines, we describe the employed techniques to determine the parameters of the multibranch model, including:

- The access resistance to the transmission line;

- The total capacity $C_{L T}$ of the transmission line;

- The total resistance $R_{L T}$ of the transmission line;

- The capacity $\mathrm{Ci}$ and the resistance $\mathrm{Ri}$ of the different complementary branches.

a) Transmission line parameters

- Access resistance $R_{1}$

Figure 5 presents the variation of the voltage $V_{s c}$ at the supercapacitors terminals, allowing us to determine the access resistance $R_{1}$ value at the transmission line. Which due to the voltage variation $\Delta V_{R 1}$ during a charge (current) application as expressed in equation (16).

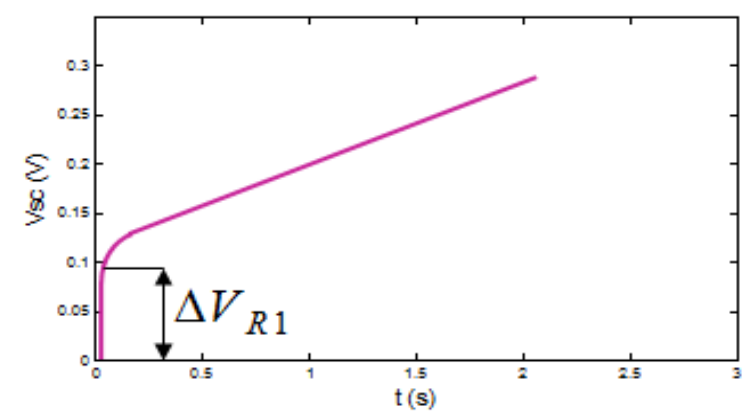

Figure 5:Portion of the curve $V_{s c}(t)$ identifying the access resistance $R_{1}$ at the transmission line 


$$
R_{1}=\frac{\Delta V_{R 1}}{I_{s c}}
$$

- Total capacity $C_{L T}$ of the transmission line

If the complementary branches are inactive, it can be concluded the total capacity $C_{L T}$ of the transmission line in function of voltage $V_{s c, c e l}$ through few partial charge tests [10]. Practically, this capacity can be determined from slope of the $V_{s c, c e l}(t)$ curve.

The capacity values $C_{L T}\left(V_{s c, \text { elem }}=0 \mathrm{~V}\right)$ and $C_{L T}\left(V_{s c \text {,elem }}=0.5 \mathrm{~V}\right)$ can be computed using the equations (17) and (18), respectively, as shown in figures 6 and 7 .

$$
\begin{gathered}
C_{C L}\left(V_{s c, e ́ l e m}=0 \mathrm{~V}\right)=\frac{I_{s c} \Delta t\left(V_{s c, \text { élem }}=0 \mathrm{~V}\right)}{\Delta V\left(V_{s c, \text { élem }}=0 \mathrm{~V}\right)} \\
C_{C L}\left(V_{s c \text {,élem }}=0.5 \mathrm{~V}\right)=\frac{I_{s c} \Delta t\left(V_{s c, \text { élem }}=0.5 \mathrm{~V}\right)}{\Delta V\left(V_{s c, \text { élem }}=0.5 \mathrm{~V}\right)}
\end{gathered}
$$

Then, it will be easy to find the expression of the transmission line capacity $C_{L T}$ by increasing the voltage from $0.5 \mathrm{~V}$ until it reaches the nominal voltage of the supercapacitor.

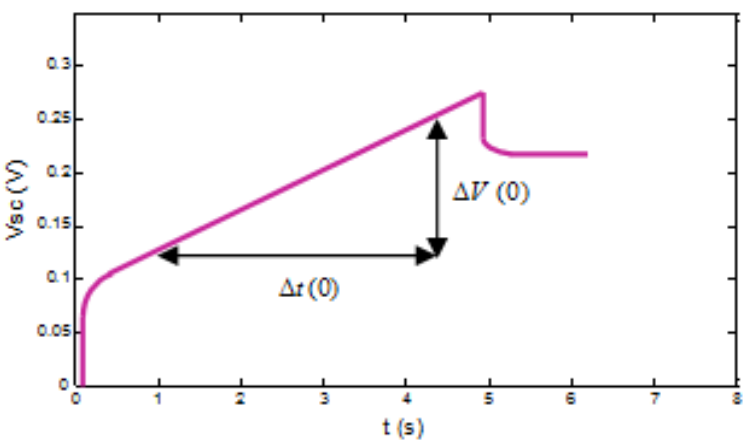

Figure 6:Portion of the curve $V s c(t)$ identifying the capacity $C_{L T}$ of the transmission line for $V_{s c, e ́ l e m ~}=0 \mathrm{~V}$

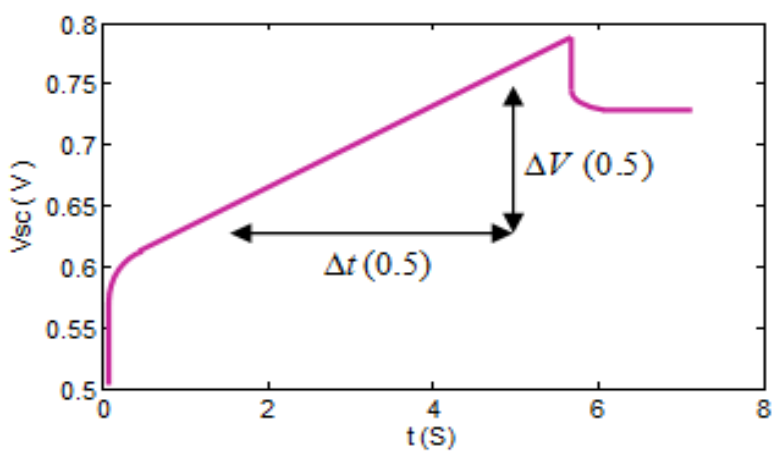

Figure 7:Portion of the curve $V s c(t)$ identifying the capacity $C_{L T}$ of the transmission line for $V_{s c \text { élem }}=0.5 \mathrm{~V}$

- Total resistance $R_{L T}$ of the transmission line

In the literature, some authorsreported that we consideran impedance approximation index to compute the resistance $R_{L T}$ of the transmission line [16], which it is a response to current of line amplitude $I_{s c}$ for very short times. From [16], this impedance can be expressed:

$$
Z_{\text {ind }}(t)=\frac{t}{C_{L T}} \sqrt{\frac{4 R_{L T}}{\pi t C_{L T}}}\left[1+2 \sqrt{\pi} \sum_{n=1}^{+\infty} \operatorname{ierfc}\left(n \frac{\tau}{t}\right)\right]
$$

With:

$$
{ }_{t} \varliminf_{+\infty} 2 \sqrt{\pi} \sum_{n=1}^{+\infty} \operatorname{ierfc}\left(\frac{\tau}{t}\right)=0
$$

Thus, the behavior of the impedance index lead us to find a law in function of $\sqrt{t}$ as expressed in equation (21):

$$
Z_{\text {ind }}(t)=\sqrt{\frac{4 R_{L T}}{\pi C_{L T}}} \sqrt{t}
$$

So, the voltage response can be written as:

$$
V_{s c, \text { élem }}(t)=R_{1} I_{s c}+Z_{\text {ind }}(t) \cdot I_{s c}
$$

Where:

$$
V_{s c, e ́ l e m}(t)=R_{1} I_{s c}+\sqrt{\frac{4 R_{L T}}{\pi C_{L T}}} I_{s c} \sqrt{t}
$$

Considering the form of a line equation as:

$$
V_{s c, e ́ l e m}(t)=A x+b
$$

Thus, $x=\sqrt{t}, A=\sqrt{\frac{4 R_{L T}}{\pi C_{L T}}} I_{S C}$ et $B=R_{1} I_{S C}$

Further, for a voltage between $0 \mathrm{~V}$ and $0.5 \mathrm{~V}$, we can determine the resistance $R_{L T}$ by measuring the slope of the voltage response in function of $\sqrt{t}$ asshown in figure 8 . It canbe computed by the following equation:

$$
R_{L T}=\frac{A^{2} \pi C_{L T}}{4 I_{s c}^{2}}
$$

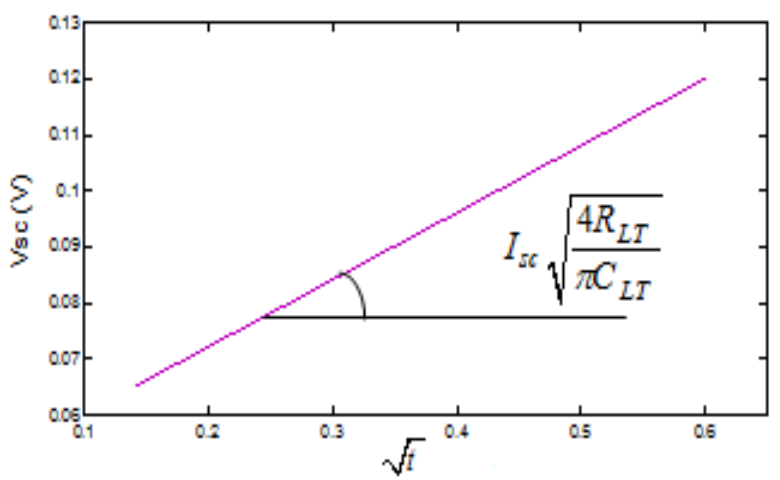

Figure 8:Portion of the curve $V_{s c}(\sqrt{t})$ identifying the total resistance $R_{L T}$ of the transmission line

b) Complementary branch parameters

It should be noted that, in this study, we use one complementary branch.

- $\quad$ Capacity $C_{\text {comp }}$

The quantity of charge $Q_{s c, \text { cel,char }}$ stored in a supercapacitor during charge phase (Figure 9) can be computed using the following formulation: 
$Q_{s c, e \text { elem, char }}=I_{s c, \text { char }} \Delta t$

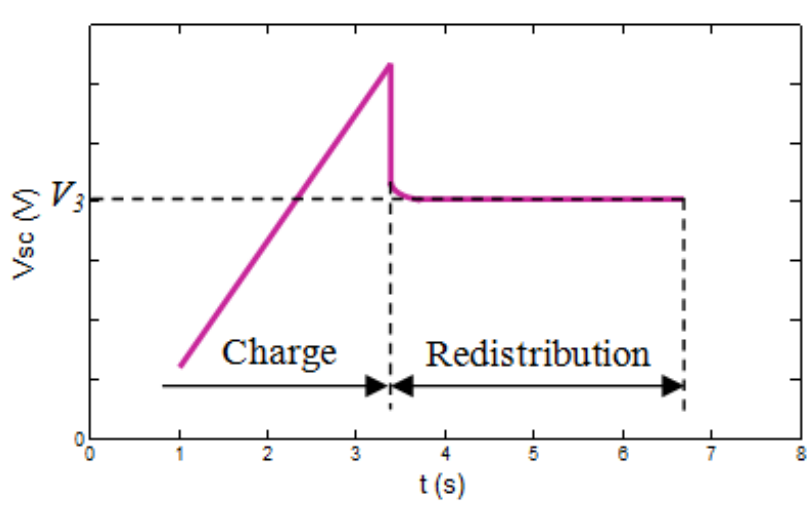

Figure 9 :Portion of the curve $V_{s c}(\sqrt{t})$ identifying the complementary capacity $\boldsymbol{C}_{\text {comp }}$

$Q_{s c, e ́ l e m, c h a r}=\int_{0}^{V_{3}} C_{L T} d V_{s c, e ́ l e m}+\int_{0}^{V_{3}} C_{c o m p} d V_{s c, \text { élem }}$

Where $V_{3}$ is the voltage at the beginning of the redistribution (Figure 9).

Where:

$$
Q_{s c, e ́ l e m, c h a r}=C_{L T, \text { moy }} V_{3}+C_{c o m p, \text { moy }} V_{3}
$$

With:

$C_{L T \text {,moy }}$ is the average value of $C_{L T}$ for a voltage interval $\left[0, V_{3}[\right.$;

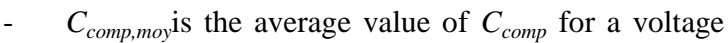
interval $\left[0, V_{3}[\right.$.

Using the equation (28), we write:

$$
C_{\text {comp ,moy }}=\frac{Q_{s c, \text { élem ,char }}}{V_{3}}-C_{L T, \text { moy }}
$$

Using the equations (27) and (28) we can write:

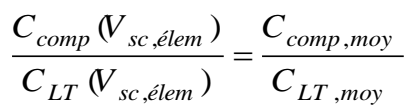

So, the capacity $C_{\text {comp }}$ can be given by the following formulation:

$$
C_{\text {comp }}\left(V_{s c, \text { élem }}\right)=\frac{C_{\text {comp ,moy }}}{C_{L T, \text { moy }}} C_{L T}\left(V_{s c, e ́ l e m ~}\right)
$$

\section{- $\quad$ Resistance $R_{\text {comp }}$}

The times constant $\tau_{\text {comp }}$ associated to the complementary branch can be expressedas follow:

$$
\tau_{\text {comp }}=R_{\text {comp }} C_{\text {comp }}
$$

Referring to Belhachemi [10], the redistribution phase cover a period equal $5 \tau_{\text {comp }}$, thus:

$$
t_{\text {redis }}=5 \tau_{\text {comp }}=5 R_{\text {comp }} C_{\text {comp }}
$$

Eventually, the resistance $R_{\text {comp }}$ can expressed as follow:

$$
R_{\text {comp }}=\frac{t_{\text {redis }}}{5 \tau_{\text {comp }}}
$$

\section{SIMULATION RESULTS}

In this section, we present the simulation results achieved by both models: RC-constructor and multibranch.Table 1 lists the electric characteristics of Maxwell supercapacitor type BCAP0010 that have a capacity of $2600 \mathrm{~F}[13,14]$ used in this study.

Table1:Electric characteristics of the supercapacitor BCAP0010

\begin{tabular}{|ll|}
\hline \multicolumn{2}{|c|}{ Specifications } \\
\hline Capacitance(F) & $2600\left(\mathrm{en} \mathrm{DC}\right.$ et $\left.25^{\circ} \mathrm{C}\right)$ \\
Capacitancetolerance & $\pm 20 \%$ \\
Voltages $(\mathrm{V}):$ & \\
$\quad$ & 2.5 \\
$\quad$ nominal & 2.8 \\
$\quad$ maximal & $0.7\left(\mathrm{en} \mathrm{DC}\right.$ et $\left.25^{\circ} \mathrm{C}\right)$ \\
Resistance inseries $(\mathrm{m} \Omega)$ & $4300($ à2.5 V) \\
Specific power density $\left(\mathrm{Wkg}^{-1}\right)$ & 600 \\
maximal current $(\mathrm{A})$ & \\
Temperature $\left({ }^{\circ} \mathrm{C}\right):$ & -35 à +65 \\
$\quad$ of operation & -35 à +65 \\
$\quad$ of storage & $10\left(\mathrm{à} 25^{\circ} \mathrm{C}\right)$ \\
Lifetime (year) & $500000\left(\right.$ at $25^{\circ} \mathrm{C}$ and $\left.I=20 \mathrm{~A}\right)$ \\
Cyclability & \\
\hline
\end{tabular}

Table 2 lists the values of the relative parameters of the RCconstructor during charge and discharge obtained for current $I_{s c, e ́ l e m}=30 \mathrm{~A}$ after several simulations.

Table 2:Parameters values of the RC-constructor model

\begin{tabular}{|c|c|c|c|c|}
\hline $\begin{array}{c}\text { Current } \\
(\mathbf{A})\end{array}$ & $\begin{array}{c}\boldsymbol{R}_{\text {sc, cel,char }} \\
(\mathbf{m} \boldsymbol{\Omega})\end{array}$ & $\begin{array}{c}\boldsymbol{C}_{\text {sc,cel,char }} \\
(\mathbf{F})\end{array}$ & $\begin{array}{c}\boldsymbol{R}_{\text {sc, cel,disc }} \\
(\mathbf{m} \boldsymbol{\Omega})\end{array}$ & $\begin{array}{c}\boldsymbol{C}_{\text {sc, cel,disc }} \\
(\mathbf{F})\end{array}$ \\
\hline 30 & 38.015 & 2523 & 32.700 & 2502 \\
\hline
\end{tabular}

For multibranch model, we obtained the following parameters values: the access resistance $R_{1}=3.2 \mathrm{~m} \Omega$, the total resistance of the transmission line $R_{L T}=22.11 \mathrm{~m} \Omega$, and the total capacity values of the transmission line $C_{L T}$, which is summarized in table 3 .

Table3: Total capacity values $C_{L T}$ of the transmission line

\begin{tabular}{|l|c|c|c|c|c|c|}
\hline $\begin{array}{l}\text { Voltage } \\
(\mathbf{V})\end{array}$ & 0 & 0.5 & 1 & 1.5 & 2 & 2.5 \\
\hline $\begin{array}{l}\text { Capacity } \boldsymbol{C}_{\boldsymbol{L} T} \\
(\mathbf{F})\end{array}$ & 1960.8 & 2354.2 & 2400.0 & 2767.8 & 3054.1 & 3054.1 \\
\hline
\end{tabular}

Using the values listed in table 3 and based on a tool implemented in Matlab software, we computed the interpolation polynomials coefficients of the order 2 and 3 that reflecting the dependency of capacity $C_{L T}$ with voltage $V_{s c, c e l}$. The polynomials functions are given by the equations (35) and (36):

$$
\begin{gathered}
C_{L T}=-71.8 V_{s c, e ́ l e m}^{2}+632.8 V_{s c, e ́ l e m}+1972(35) \\
C_{L T}=-67 V_{s c, \text { élem }}^{3}+179.3 V_{s c, \text { élem }}^{2}+403.5 V_{s c, \text { élem }}+1997.1
\end{gathered}
$$

In order to compare $C_{L T}$ values listed in table 3 and those may computed by using the equation (35) and (36), we presented the curve of the polynomials functions of $C_{L T}$ in function of 
the voltage $V_{s c, c e l}$ of the supercapacitor (Figure 10).

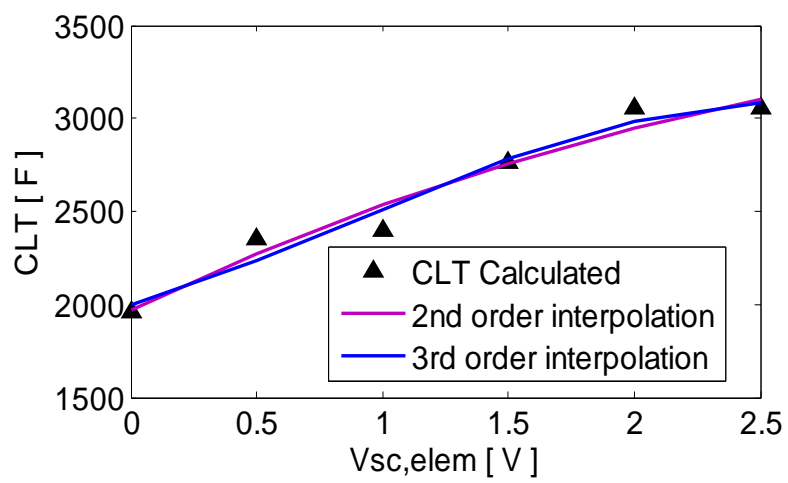

Figure 10:Polynomials variations of $C_{L T}$ in function of $V_{s c, c e l}$

In general, the complementary branches representing charge redistributionare characterized by times constant relatively very high of that of the transmission line. Note of that, in this study, contrary to what commonly used in literature [16], we used one complementary branch.

The obtained parameters values are: the complementary branch resistance $R_{\text {comp }}=67.6 \mathrm{~m} \Omega$, and the complementary capacity values $C_{\text {comp }}$ are listed in table 4 .

Table 4 :Complementary capacity values $\boldsymbol{C}_{\text {comp }}$

\begin{tabular}{|l|c|c|c|c|c|c|}
\hline $\begin{array}{l}\text { Voltage } \\
(\mathbf{V})\end{array}$ & 0 & 0.5 & 1 & 1.5 & 2 & 2.5 \\
\hline $\begin{array}{l}\text { Capacity } \boldsymbol{C}_{\text {comp }} \\
\text { (F) }\end{array}$ & 50.78 & 60.97 & 62.16 & 71.68 & 88.62 & 88.62 \\
\hline
\end{tabular}

We useda tool implemented in Matlab software to generating the interpolation polynomials coefficients based on parameters values listed in table 4 . The equations (37) and (38) given the polynomials functions of the order 2 and 3 , respectively, which represent the evolution of the complementary capacity $C_{L T}$ in function of voltage $V_{\text {sc,elem }}($ Figure 11).

$$
\begin{gathered}
C_{\text {comp }}=0.8598 V_{s c, \text { élem }}^{2}+13.945 V_{s c, \text { élem }}+51.07 \text { (37) } \\
C_{\text {comp }}=-3.1431 V_{s c, \text { élem }}^{3}+12.6463 V_{s c, \text { élem }}^{2}+3.18 V_{s c, \text { élem }}+52.25
\end{gathered}
$$

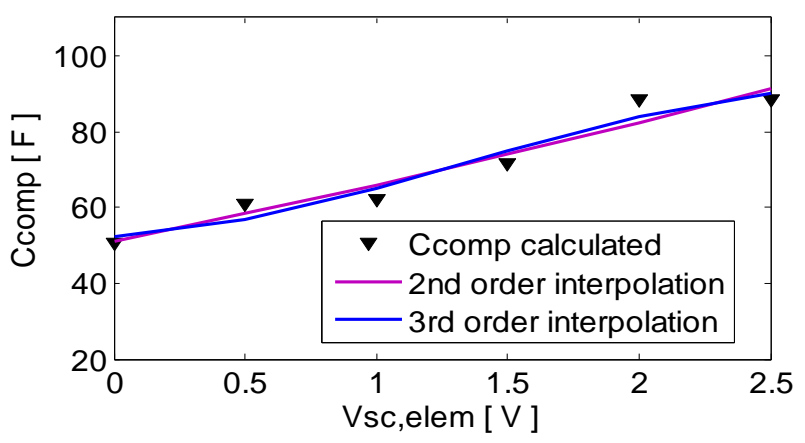

Figure 11: Complementary capacity $C_{c o m p}$ evolution in function of $V_{\text {sc,elem }}$

Figure 12 and table 5 shows the evolution of the voltage $V_{s c, e l e m}$ for a current $I_{S C \text {,élem }}= \pm 30 \mathrm{Abased}$ on RC-constructor model and multibranch model. Note of that the number of branch used in multibranch model are 14 that gives best results.
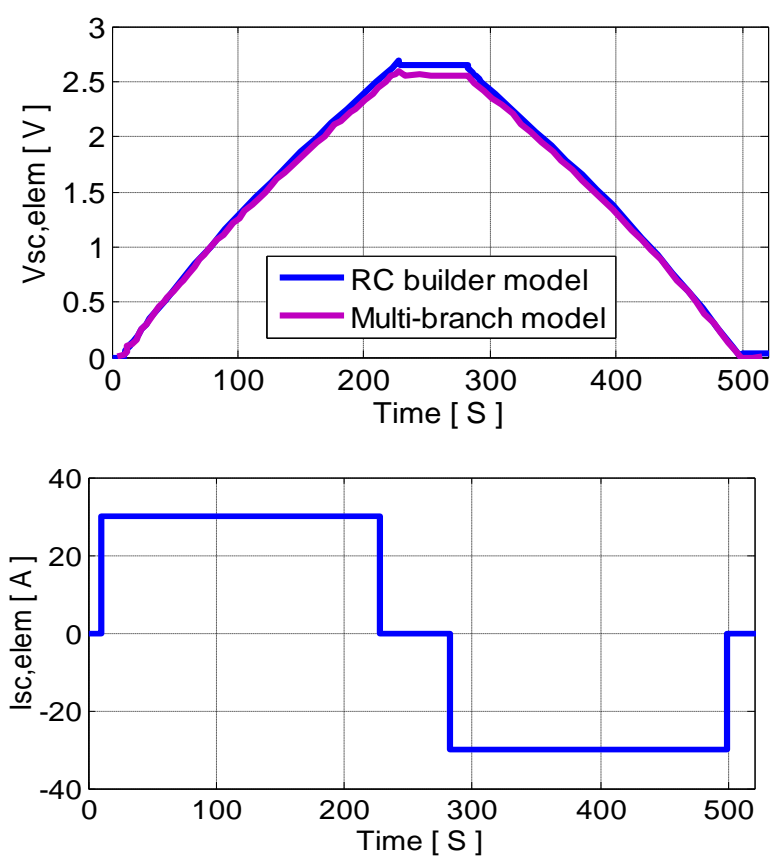

Figure 12: Evolution of $V_{s c, e l e m}$ and $I_{s c, \text { elem }}$ of the supercapacitor BCAP0010

In fact, there are similarity between the simulation results of both models with lower difference noted between $t=220 \mathrm{~s}$ and $t=280 \mathrm{~s}$ (Figure 12).

Table 5:The values of $V_{s c, e l e m}$ as a function of timeof the supercapacitor BCAP0010

\begin{tabular}{|c|c|c|}
\hline & \multicolumn{2}{|c|}{ Vsc,elem (V) } \\
\hline Time (s) & $\begin{array}{c}\text { RC- } \\
\text { constructor } \\
\text { model }\end{array}$ & $\begin{array}{c}\text { Multibranch } \\
\text { model }\end{array}$ \\
\hline 50 & 0.68 & 0.63 \\
\hline 100 & 1.29 & 1.23 \\
\hline 150 & 1.86 & 1.82 \\
\hline 200 & 2.38 & 2.34 \\
\hline 250 & 2.65 & 2.55 \\
\hline 300 & 2.39 & 2.35 \\
\hline 350 & 1.91 & 1.86 \\
\hline 400 & 1.37 & 1.24 \\
\hline 450 & 0.66 & 0.64 \\
\hline 500 & 0 & 0 \\
\hline
\end{tabular}

\section{CONCLUSION}

In this paper, we have presented the characterization and modeling of supercapacitors. These devices can be used for the storage of electrical energy in a hybrid or multi-source renewable energy system and can be used in complementary ways to batteries to extend their lifetime. For this, we used 
two models, namely: the "RC-Constructor" model and the "Multi-branch" model.The obtained results show that there is similarity between the simulation results of the two models.This will make it possible to predict the electrical behavior of supercapacitors based on these studied models. The perspective of this work is to validate this simulation by experimental measurements.

\section{REFERENCES}

[1] Mamadou Bailo CAMARA, "Super-condensateurs pour échange dynamique d'énergie au bord du véhicule électrique hybride", Doctoral Thesis, University FrancheComté, France, 2007.

[2] Mohamed Ansouman Camara, "Modélisation du stockage de l'énergie photovoltaïque par Supercondensateurs", Doctoral Thesis, University Paris Est Créteil, France, 2011.

[3] Mohamed Yassine Ayad, "Mise en œuvre des Supercondensateurs dans les sources hybrides continues", Doctoral Thesis, National Polytechnic Institute of Lorraine, 2004

[4] O. Gergaud, "Modélisation énergétique et optimisation économique d'un système de production éolien et photovoltaïque couplé au réseau et associé à un accumulateur", Doctoral Thesis,the Higher School of Cachan,France, 2002.

[5] A. Ould Mahmoud Yahya et I. Youm, "Modélisation d'un système de stockage intégré dans un système hybride (PV/Eolien/Diesel)", Revue des Energies Renouvelables, Vol. 10,No2, 2007,pp. 205-214.

[6] N. Achaibou, M.Haddadi, A.Malek, "Modeling of lead acid batteries in PV systems", Energy Procedia,Vol. 18, Issue 2012,pp. 538-544.

[7] Achaibou Nadia, Harikenchikh Ali, "Solar Electricity Storage in Lead Acid Batteries", InternationalRenewable and Sustainable Energy Conference (IRSEC),
Ouarzazate,Morocco, March7-9, 2013.

[8] IonelVechu, "Modélisation et analyse de l'intégration des énergies renouvelables dans un réseau autonome", Doctoral Thesis, Universityof Havre, France, 2005.

[9] Hamid Gualous, Roland Gally, "Applications des supercondensateurs", Techniques de l'ingénieur Génie Electrique, 2008, D3335, p. 4.

[10] Damien Paire, "Dimensionnement et gestion d'énergie de systèmes d'entrainements électriques hybrides: Application à un ascenseur avec récupération d'énergie", Doctoral Thesis, University of Technology, BelfortMontbéliard, France, 2010.

[11] Amine Lahyani, Pascal Venet, Abdessattar Guermazi, and Alaeddine Troudi, "Battery/Supercapacitors Combination in Uninterruptible Power Supply (UPS)", IEEE Transaction on Power Electronics, Vol. 28, No. 4,2013, pp. 1509-1522.

[12] W. Choi, J. W. Howze, P. Enjeti,"Fuel-cell powered uninterruptible power supply systems: Design considerations", Journal of Power Sources, Vol. 157, No 1, 2006, pp. 311-317.

[13] Maxwell technology, "Representative Test Procedure for Customer Evaluation (Application Note)", www.maxwell.com, Mach 2002.

[14] Maxwell technology, "BoostcapUltracapacitor Module Operating Manual", www.maxwell.com, January 2003.

[15] Nathalie Devillers, Samir Jemei, Marie-Cécile Péra, Daniel Bienaimé, FrédéricGustin,"Review of characterization methods for supercapacitor modeling", Journal of Power Sources, Vol. 246, 2014, pp. 596-608.

[16] Farid Belhachemi, "Modélisation et caractérisation des Super-condensateurs à couche double électrique utilisés en électronique de puissance", Doctoral Thesis, National Polytechnic Institute of Lorraine, France, 2001. 